\title{
Percutaneous endoscopic cervical laminectomy
}

\author{
Yasuhiko Nishimura \\ Spinal Surgery Center, Department of Neurosurgery, Wakayama Koyo Hospital, Wakayama 640-8315, Japan.
}

Correspondence to: Dr. Yasuhiko Nishimura, Spinal Surgery Center, Department of Neurosurgery, Wakayama Koyo Hospital, Wakayama 640-8315, Japan. E-mail: nishimuray@koyo-hosp.jp

How to cite this article: Nishimura Y. Percutaneous endoscopic cervical laminectomy. Mini-invasive Surg 2017;1:69-73.

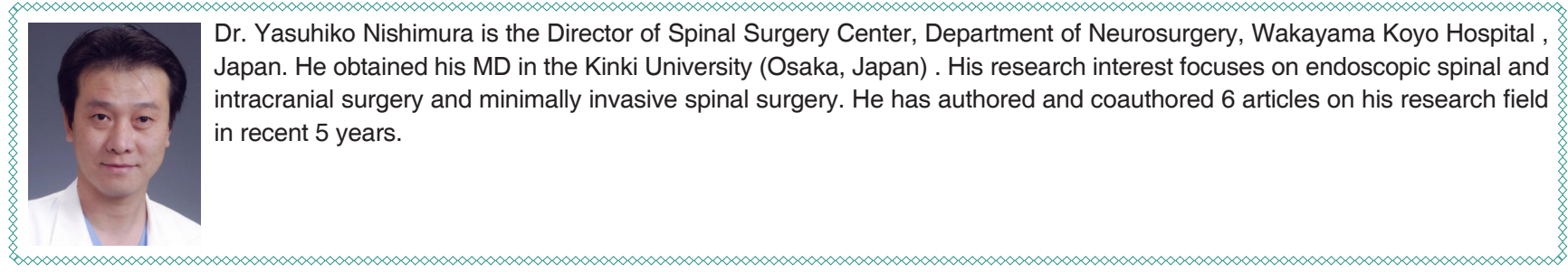

Article history:

Received: 05-03-2017

Accepted: 26-05-2017

Published: 30-06-2017

Key words:

Percutaneous endoscopic cervical laminectomy,

cervical spinal canal stenosis, myelopathy, minimally invasive

\section{ABSTRACT}

\begin{abstract}
Aim: This study aimed to document the use of percutaneous endoscopic cervical laminectomy (PECL) and the treatment results. Methods: Eleven patients with a limited cervical spinal canal stenosis were indicated for the surgery. Under general anesthesia, the interlaminar space between the affected vertebrae was approached from $5 \mathrm{~mm}$ outside the midline. Laminectomy was performed using a 2.5-mm or 3.5-mm high speed drill, and an endoscope. Subsequently, the bilateral yellow ligament was removed and sufficient decompression of the dural sac was confirmed. Surgery was completed after the placement of an indwelling drain. Pre- and postoperative statuses were evaluated using the modified Japanese Orthopedic Association (mJOA) score. Results: The mean operation time was $87.1 \mathrm{~min}$, and no complications were observed. During the mean follow-up period of 16.6 months, the mJOA score improved significantly from $10.9 \pm 0.7$ to $14.3 \pm 1.3(P=0.0000002)$. Conclusion: PECL is a minimally invasive surgical technique for cervical posterior decompression. This is a useful procedure, although it is technically demanding, and must be carefully performed under strict indication by a surgeon with sufficient experience of endoscopic techniques.
\end{abstract}

\section{INTRODUCTION}

Cervical posterior decompression is an accepted surgical method to treat cervical spinal canal stenosis, although the technique has various problems. ${ }^{[1]}$ For example, postoperative axial neck pain is reported in $30 \%$ of patients at a mean follow-up of 51 months. ${ }^{[2]}$ The current study aimed to investigate minimally invasive cervical spine surgery and the use of endoscopy for this spinal surgery.

Recently, because of advances in endoscope resolution and digital processing capabilities, percutaneous endoscopes that are used at the lumbar

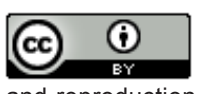

and reproduction
identical terms.

For reprints contact: service@oaepublish.com

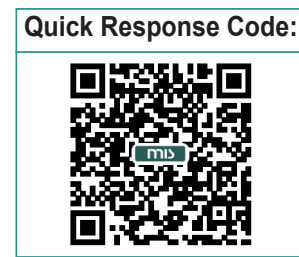


level can also be used safely at the level of the cervical spine. ${ }^{[3]}$ Therefore, the use of such endoscopes has been expanded to the level of the cervical cord, and surgeons have begun to carry out this procedure in Japan. This procedure is expected to be adopted more widely in the future. Surgeon at the current institution hasperformed percutaneous endoscopic cervical laminectomy (PECL) and has obtained good results. Here, this surgical technique and treatment outcomes are reported.

\section{METHODS}

\section{Operative indication}

Indication for the surgery included one vertebral disc level of cervical spinal canal stenosis, with the factor for stenosis being the thickening of the yellow ligament from the posterior, or stenosis because of protrusion of a cervical disc. This procedure has not been applied to complicated and/or widely extended canal stenosis and re-operative cases.

\section{Preparation}

An angled endoscope (15 and 25 degrees: Karl Storz $\mathrm{GmbH}$, Tuttlingen, Germany) was used, which was also used to treat lumbar diseases in this department. A square endoscopic sheath and a high-speed drill (the burr head diameter is $2.5 \mathrm{~mm}$ or $3.5 \mathrm{~mm}$, NSKNakanishi Japan, Tokyo, Japan) were also used. For excision of the yellow ligament, a punch (cutter), forceps, and curette, or a small bipolar radio-frequency electrode system (Elliquence, Baldwin, NY, USA) was used.

General anesthesia is recommended because the surgery time and drill usage time are long and a strict rest is necessary for safe surgery. Combined use of free run motor evoked potential for transcranial irritation is also recommended. ${ }^{[4]}$

Perfusion pressure is important because the surgery is performed near the cranial epidural space. The optimal perfusion pressure is $100 \mathrm{cmH}_{2} \mathrm{O}$ and the height of free drip is kept at $150 \mathrm{~cm}$ during the surgery.

\section{Operative procedure}

The surgical position is similar to that of a cervical laminoplasty. After fixation of the head using a Mayfield clamp, the posture is the Concorde style. The cervical spine is fixed in the neutral position. The approach is outside-in from the back, similar to the percutaneous endoscopic lumbar discectomy interlaminar approach. ${ }^{[5]}$ The approach side is the side where myelopathy is dominant, but if there is no difference between the left and right, it is recommended to approach from the left side, because a right-handed surgeon stands on the patient's left side for surgery.

In the interlaminar space between the affected vertebrae, a skin incision of 6 to $8 \mathrm{~mm}$ is made 5 $\mathrm{mm}$ outside the midline, with an incision of 6 to $8 \mathrm{~mm}$ made on the fascia. While gently rotating and vertically piercing the dilator to this incision, either the upper or lower margin of the arcus vertebrae is checked by sensing contact with the bone using the tip of the dilator. At this position, the operating sheath is replaced using a dilator. ${ }^{[6,7]} \mathrm{A}$ small amount of muscle tissue in the interlaminar space is retracted using the bipolar coagulator or resected with forceps to expose the face of the yellow ligament of the interlaminar space. As this yellow ligament acts as a protector when the drill slips, it should be preserved as much as possible until bone removal is completed. Bone removal is started from either the lower margin of the superior arcus vertebrae or the upper margin of the inferior arcus vertebrae. Because the purpose of decompression is release from the pincer mechanism of the thickened yellow ligament on the spinal cord, bone removal in the part covering the thickened yellow ligament region is sufficient. ${ }^{\left[{ }^{[}\right]}$

Although it depends on gender and physique, the anatomical range of existence of the yellow ligament is usually exposed by removing 5-6 $\mathrm{mm}$ of the superior vertebrae and 3-4 $\mathrm{mm}$ of the inferior vertebra. It is normally unnecessary to remove the contralateral arcus vertebrae. Because the approach is $5 \mathrm{~mm}$ away from the median, it is possible to pull down the operating sheath so that the region under the contralateral arcus vertebrae can be sufficiently observed. However, in the event that it cannot be pulled down sufficiently, it is necessary to remove the bone in the ventral inner edge of the contralateral arcus vertebrae [Figure $1 \mathrm{I}$ and $\mathrm{J}]$.

Leaving the yellow ligament on the approach side, remove the yellow ligament on the contralateral side at first, because if the ligament on the approach side is removed first, the dura is exposed and expanded and this is dangerous and also hinders the visual field. If the yellow ligament is resected by approximately 5 $\mathrm{mm}$ from the median to the contralateral side, the half spinal cord on the contralateral side is decompressed. Subsequently, resection of the approach side yellow ligament is performed. Except for cases in which stenosis of the vertebral foramen on the approach side is complicated, the bone removal range and resection range for the yellow ligament on the approach side are sufficient up to the inside of the facet joint. If it is difficult to stop bleeding, a head-up position is effective. Surgery is completed after the placement of an indwelling drain, which is considered essential. ${ }^{[9]}$ 
Table 1: Summary of the detailed features of the 11 cases with PECL

\begin{tabular}{|c|c|c|c|c|c|c|c|c|c|c|c|c|}
\hline $\begin{array}{l}\text { Case } \\
\text { No. }\end{array}$ & $\begin{array}{l}\text { Age, } \\
\text { years }\end{array}$ & Gender & $\begin{array}{l}\text { Original } \\
\text { disease }\end{array}$ & $\begin{array}{c}\text { Affected } \\
\text { level }\end{array}$ & $\begin{array}{l}\text { Approach } \\
\text { side }\end{array}$ & $\begin{array}{l}\text { Operation } \\
\text { time, min }\end{array}$ & $\begin{array}{c}\text { Hospital } \\
\text { stay, } \\
\text { days }\end{array}$ & $\begin{array}{l}\text { Follow-up } \\
\text { periods, } \\
\text { months }\end{array}$ & Complication & $\begin{array}{c}\text { mJOA } \\
\text { score } \\
\text { pre-op }\end{array}$ & $\begin{array}{c}\text { mJOA } \\
\text { score } \\
\text { post-op }\end{array}$ & $\begin{array}{c}\text { Recovary } \\
\text { rate, \% }\end{array}$ \\
\hline 1 & 59 & Male & HYL & $\mathrm{C} 5 / 6$ & Left & 96 & 5 & 28 & No & 11 & 15 & 66.7 \\
\hline 2 & 61 & Male & HYL + Disc & $\mathrm{C} 4 / 5$ & Left & 81 & 5 & 25 & No & 10.5 & 13 & 36.5 \\
\hline 3 & 67 & Male & OPLL & $\mathrm{C} 5 / 6,6 / 7$ & Right & 141 & 5 & 24 & No & 11 & 15 & 66.7 \\
\hline 4 & 72 & Female & HYL + Disc & $\mathrm{C} 4 / 5$ & Right & 85 & 8 & 20 & No & 10 & 13 & 42.9 \\
\hline 5 & 58 & Male & HYL & $\mathrm{C} 3 / 4$ & Left & 70 & 3 & 17 & No & 11.5 & 16 & 81.8 \\
\hline 6 & 65 & Female & HYL & C3/4 & Right & 74 & 5 & 17 & No & 12 & 15 & 60.0 \\
\hline 7 & 71 & Female & OPLL & $C 4 / 5$ & Right & 75 & 8 & 13 & No & 11.5 & 16 & 81.8 \\
\hline 8 & 76 & Male & HYL + Disc & $\mathrm{C} 5 / 6$ & Right & 82 & 8 & 12 & No & 11 & 13 & 33.3 \\
\hline 9 & 69 & Male & HYL & $\mathrm{C} 5 / 6$ & Left & 95 & 8 & 10 & No & 10 & 13 & 42.9 \\
\hline 10 & 52 & Male & OPLL & C6/7 & Left & 88 & 3 & 10 & No & 11 & 15 & 66.7 \\
\hline 11 & 59 & Female & HYL & $\mathrm{C} 5 / 6$ & Left & 71 & 5 & 7 & No & 10 & 13 & 42.9 \\
\hline
\end{tabular}

PECL: percutaneous endoscopic cervical laminectomy; mJOA: modified Japanese Orthopaedic Association; HYL: hypertrophic yellow ligament; Disc: cervical disc protrusion; OPLL: oscificated posterior longitiduinal ligament

\section{Data analysis}

Pre- and postoperative neurological statuses were evaluated using the modified Japanese Orthopaedic Association (mJOA) score for cervical myelopathy. Recovery rate was calculated as follows: recovery rate = postoperative $\mathrm{mJOA}$ - preoperative $\mathrm{mJOA} / 17$ (full score) - preoperative mJOA score $\times 100 .{ }^{[10,11]}$ Statistical analysis was performed using Student's $t$-test. $P$ values less than 0.05 were considered statistically significant.

This retrospective study was approved by the ethics committee of the Wakayama Koyo Hospital, and informed consent was obtained from the patients for publication of this study and any accompanying images. The procedures were in accordance with the ethical standards of the committee and with the Helsinki Declaration.

\section{RESULTS}

Eleven patients were registered for this study. The mean age was 64.5 years (range $52-76$ years) and the male/female ratio was $7 / 4$. The most affected vertebral level was C5/6 ( 5 cases), followed by C4/5 (3 cases). Detailed information on each case, such as operation time, follow-up period, and hospital stay, is shown in Table 1.

During the mean follow-up period of 16.6 months (range 7-28 months), the mJOA score improved significantly

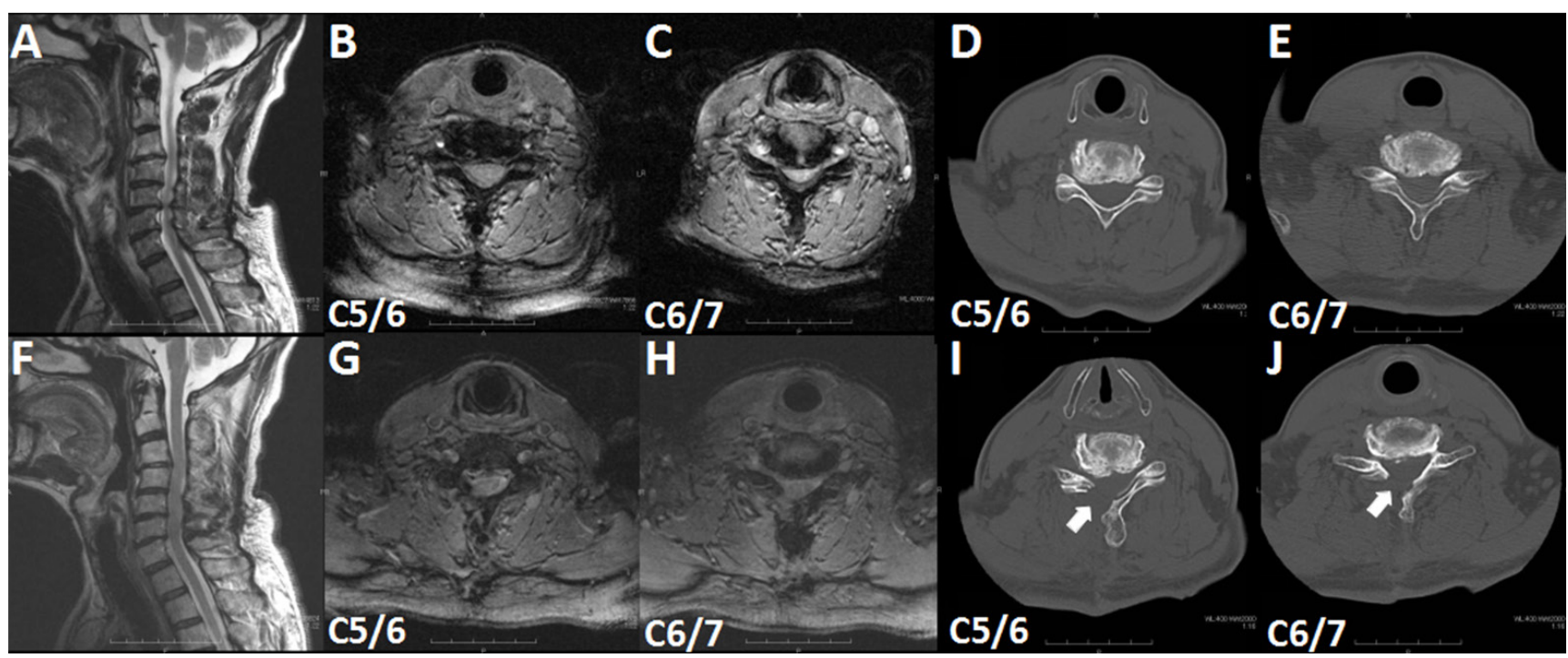

Figure 1: T2-weighted magnetic resonance imaging $(A, B, C, F, G, H)$ and computed tomography $(D, E, I, J)$ findings of a patient with oscificated posterior longitiduinal ligament (case 3). (A, B, C, D, E) Preoperative images; (F, G, H, I, J) postoperative images. (A, F) Sagittal images; (B, C, D, E, G, H, I, J) axial images. Arrows in (I, J) indicate the removed right vertebral laminae 
from $10.9 \pm 0.7$ to $14.3 \pm 1.3(P=0.0000002)$. The mean recovery rate was $56.6 \pm 17.6 \%$. The mean operation time was $87.1 \mathrm{~min}$ (range 70-141 min), and neitherintra- nor postoperative complications were observed. The mean hospital stay was 5.7 days (range 3-8 days), and all patients were discharged.

A representative case (case 3 ) is shown in Figure 1. A 67-year-old man complained of progressive worsening of numbness of both upper extremities and impairment of skillful movementand walking. A neurological examination revealed an increase in all tendon reflexes, moderate muscle weakness (grasp strength: right, $18 \mathrm{~kg}$; left, $27 \mathrm{~kg}$ ), and a sensory disturbance. Sagittal cervical magnetic resonance imaging (MRI) revealed central canal stenosis at the $\mathrm{C} 5 / 6$ and $\mathrm{C} 6 / 7$ intervertebral disc levels [Figure 1A-C]. PECL was performed, and all symptoms improved to some extent (grasp strength: right, $24 \mathrm{~kg}$; left, $29 \mathrm{~kg}$ ) 4 weeks after PECL. Postoperative MRI revealed enlargement of the corresponding spinal canal [Figure $1 \mathrm{~F}-\mathrm{H}]$. A comparison of preoperative [Figure 1D and E] and postoperative [Figure $1 \mathrm{I}$ and $\mathrm{J}$ ] computed tomography findings demonstrates the extent of the laminectomy (arrows).

\section{DISCUSSION}

PECL is a surgical technique that can be used to enlarge and shape a narrowed spinal canal without destroying the spinal structure and supporting elements more than conventional microscopic laminoplasty, namely cervical micro endoscopic laminectomy. ${ }^{[12-15]}$ However, the technique does have some disadvantages and requires a drill to be used in a surgical field of approximate $1 \mathrm{~cm}^{3}$ and resection of the yellow ligaments is performed via this small bone window. Therefore, this operation takes a lot of time and causes some operator fatigue. It is recommended that PECL should be carefully performed by the surgeon using a sufficient endoscopic technique. In this study, case 3 was the only case involving multilevel stenosis. The operation time was $141 \mathrm{~min}$ and is significantly longer than surgeries involving single level stenosis (mean operation time is $81.7 \mathrm{~min}$ ). Therefore, it is also recommended that PECL should currently be performed only for single level stenosis.

In conclusion, the current study has reported on the experience of surgeon in this department with PECL, a minimally invasive cervical posterior decompression surgical technique. This is a useful procedure, although it is a surgery that surgeons with sufficient endoscopic technique must perform carefully under strict indication.

\section{Authors' contributions}

Y. Nishimura contributed solely to the paper.

\section{Financial support and sponsorship}

None.

\section{Conflicts of interest}

There are no conflicts of interest.

\section{Patient consent}

Informed consent was obtained from the patients for publication of this study and any accompanying images.

\section{Ethics approval}

This study was approved by the ethics committee of the Wakayama KOYO Hospital and the procedures were in accordance with the ethical standards of the committee and with the Helsinki Declaration.

\section{REFERENCES}

1. Ito M, Nagahama K. Laminoplasty for cervical myelopathy. Global Spine J 2012;2:187-94.

2. Duetzmann S, Cole T, Ratliff JK. Cervical laminoplasty developments and trends, 2003-2013: a systematic review. J Neurosurg Spine 2015;23:24-34.

3. Ruetten S, Komp M, Merk H, Godolias G. Full-endoscopic cervical posterior foraminotomy for the operation of lateral disc herniations using 5.9-mm endoscopes: a prospective, randomized, controlled study. Spine (Phila Pa 1976) 2008;33:940-8.

4. Nakagawa Y, Yoshida M, Yamada H. Perioperative complications associated with cervical microendoscopic laminoplasty (CMEL) for cervical myelopathy patients. Society for Minimally Invasive Spine Surgery (SMSS); 2012.

5. Tonosu J, Oshima Y, Shiboi R, Hayashi A, Takano Y, Inanami H, Koga H. Consideration of proper operative route for interlaminar approach for percutaneous endoscopic lumbar discectomy. $J$ Spine Surg 2016;2:281-8.

6. Adamson TE. Microendoscopic posterior cervical laminoforaminotomy for unilateral radiculopathy: results of a new technique in 100 cases. J Neurosurg 2001;95:51-7.

7. Yabuki S, Kikuchi S. Endoscopic surgery for cervical myelopathy due to calcification of the ligamentum flavum. $J$ Spinal Disord Tech 2008;21:518-23.

8. Nakagawa Y. Cervical microendoscopic laminoplasty for cervical myelopathy. Spine Spinal Cord 2015;28:799-807.

9. Nishimura Y, Lubbers T. Perkutane endoskopische dorsale HWSDekompression. Wirbelsaule interdisziplinar, Schattauer; 2017. p. 424-6.

10. Hirabayashi K, Miyakawa J, Satomi K, Maruyama T, Wakano K. Operative results and postoperative progression of ossification among patients with ossification of cervical posterior longitudinal ligament. Spine (Phila Pa 1976) 1981;6:354-64.

11. Hirabayashi K, Watanabe K, Wakano K, Suzuki N, Satomi K, Ishii Y. Expansive open-door laminoplasty for cervical spinal stenotic myelopathy. Spine (Phila Pa 1976) 1983;8:693-9.

12. Oshima Y, Takeshita K, Inanami H, Takano Y, Koga H, Iwahori 
T, Baba S, Tanaka S. Cervical microendoscopic interlaminar decompression through a midline approach in patients with cervical myelopathy: a technical note. J Neurol Surg A Cent Eur Neurosurg 2014;75:474-8.

13. Zhang C, Li D, Wang C, Yan X. Cervical endoscopic laminoplasty for cervical myelopathy. Spine (Phila Pa 1976) 2016;41 Suppl 19:B4451.
14. Minamide A, Yoshida M, Yamada H, Nakagawa Y, Maio K, Kawai M, Iwasaki H. Clinical outcomes of microendoscopic decompression surgery for cervical myelopathy. Eur Spine J 2010;19:487-93.

15. Yoshida M, Tamaki T, Kawakami M, Hayashi N, Ando M. Indication and clinical results of laminoplasty for cervical myelopathy caused by disc herniation with developmental canal stenosis. Spine (Phila Pa 1976) $1998 ; 23: 2391-7$. 